\title{
Development of Human Interleukin-6 electrochemical Immunosensor Based on Pt-Pd Nanocomposite for Evaluation of Intervertebral Disc Degeneration
}

\author{
Fan Ding ${ }^{l}$ and Xia $\mathrm{Li}^{2, *}$ \\ ${ }^{1}$ Department of Orthopaedic Surgery, The First People's Hospital of Jingmen, Jingmen, Hubei, \\ 448000, P.R. China \\ ${ }^{2}$ Department of Ophthalmology, The First People's Hospital of Jingmen, Jingmen, Hubei, 448000, \\ P.R. China \\ *E-mail: xiali_jingmen@foxmail.com
}

doi: $10.20964 / 2017.12 .79$

Received: 17 October 2016 / Accepted: 13 October 2017 / Published: 12 November 2017

To detect interleukin-6 (IL-6) antigen, a simple immunosensor with ultra-sensitivity was prepared. A wide linear response to IL-6 was observed with the immunosensor in range of $0.1-200 \mathrm{pg} / \mathrm{mL}$, where the limit of detection was $0.032 \mathrm{pg} / \mathrm{mL}$. The method described in this work, which exhibited remarkable accuracy, excellent reproducibility, comparable stability and wide linear range, can be employed to detect IL-6 in practical specimens, where these were promising in the field of evaluating intervertebral disc degeneration.

Keywords: Platinum; Palladium; Interleukin; Intervertebral disc degeneration

\section{$\underline{\text { FULL TEXT }}$}

(C) 2017 The Authors. Published by ESG (www.electrochemsci.org). This article is an open access article distributed under the terms and conditions of the Creative Commons Attribution license (http://creativecommons.org/licenses/by/4.0/). 